\title{
SOBRE MULHERES BRABAS: RITUAL, GÊNERO E PERSPECTIVA
}

Júlia Otero dos Santos (D)

Universidade Federal do Pará. Programa de Pós-Graduação

em Antropologia I Belém - PA - Brasil 


\section{RESUMO}

O chão etnográfico deste artigo é o Wayo 'at Kanã, uma festa de mulheres realizada pelos Karo-Arara. Ofereço uma descrição e uma análise do ritual, por acreditar que, neste espaço-tempo, a agência feminina se faz mostrar em uma outra face, avessa a qualquer caracterização de domesticidade, interioridade ou consanguinidade, atribuições ordinárias para o universo feminino na etnologia sul-americana. O que esta festa faz aparecer, quando lida do ponto de vista de uma outra festa com a qual mantém uma relação um tanto quanto especular, é a alteridade imanente à posição feminina e à capacidade predatória das mulheres. A reflexão aqui apresentada também é uma formulação inicial sobre a relação entre perspectiva e gênero. A partir da interpretação do ritual, presumo a existência de uma variação entre um (ou dois) ponto(s) de vista determinado(s) pelo gênero e um ponto de vista humano, que eclipsa o gênero.

Palavras-chave: Amazônia; ritual; gênero; mulheres indígenas; predação.

\section{ABOUT FIERCE WOMEN: RITUAL, GENDER AND PERSPECTIVE}

\section{ABSTRACT}

The ethnographic ground of this work is the Wayo 'at Kanã, a women's party held by the Karo-Arara. I offer a description and an analysis of the ritual because I believe that in this spacetime the female agency is shown on another face, one that is averse to any characterization of domesticity, interiority or consanguinity, ordinary attributions to the female universe in southern American ethnology. What this party makes appear, when read from the point of view of another party with which it has a somewhat specular relationship, is the immanent alterity to the female position and the predatory capacity of women. The reflection presented here is also an initial formulation of the relationship between perspective and gender. From the interpretation of the ritual, I assume there is a variation between one (or two) gender-determined viewpoint(s) and a human viewpoint that eclipses gender.

Keywords: Amazon; ritual; gender; indigenous women; predation

\section{SOBRE MUJERES BRABAS: RITUAL, GÉNERO Y PERSPECTIVA}

La base etnográfica de este trabajo es el Wayo 'at Kanã, una fiesta de mujeres realizada por los Karo-Arara. Ofrezco una descripción y un análisis del ritual que consideran que en este espacio-tiempo la agencia femenina aparece con una nueva faceta, contraria a cualquier caracterización de domesticidad, interioridad o consanguinidad, atribuciones comunes al universo femenino en la etnología suramericana. Lo que revela esta fiesta, cuando se lee desde el punto de vista de otra fiesta con la que guarda una relación un tanto especular, es la alteridad inmanente a la posición femenina y la capacidad depredadora de las mujeres. La reflexión aquí presentada es también una formulación inicial de la relación entre perspectiva y género. A partir de la interpretación del ritual, planteo que existe una variación entre uno (o dos) punto(s) de vista determinados por el género y un punto de vista humano que eclipsa al género.

Palabras clave: Amazonia, ritual, género; mujeres indígenas, depredación. 


\section{INTRODUÇÃO: LUGAR(ES) DO GÊNERO NA ETNOLOGIA INDÍGENA}

Por muitas décadas, a produção em etnologia indígena das terras baixas sul-americanas ignorou ou conferiu um lugar marginal ao gênero. Mesmo no auge da antropologia feminista das décadas de 1970 e 1980, as relações de gênero raramente foram o foco explícito da descrição e da análise antropológica. Quando apareciam nas etnografias, eram como um subproduto irrefletido das relações de complementaridade entre capacidades produtivas masculinas e femininas, que invariavelmente sustentam a economia doméstica nas sociedades ameríndias. As exceções a esse desinteresse pelo gênero são os trabalhos voltados para a compreensão do que se convencionou chamar de antagonismo sexual, definido por Lasmar (1999:7) como "uma ideologia sustentada por um complexo míticoritual que tematiza a oposição entre os sexos, enfatizando as diferenças em termos de poder e status". A oposição e a hostilidade entre os sexos - compreendidas, muitas vezes, sob um ponto de vista psicologizante, sustentado pela ideia de uma frustração coletiva masculina decorrente das capacidades reprodutivas femininas - são o eixo de análise dos trabalhos de Yolanda e Robert
Murphy (1974) sobre os Munduruku e de Thomas Gregor (1985) sobre os Mehinaku.

Uma compreensão do gênero na Amazônia desassociada da ideia de antagonismo entre os sexos e do debate acerca da dominação (universal) masculina - sendo este o problema central da antropologia do gênero da década de 1970 - parece ter sido possibilitada pela crítica demolidora de Overing (1986) aos pressupostos implícitos na discussão levada a cabo até então, excessivamente centrada no paradigma ocidental das relações de poder. A autora mostra como a compreensão sobre gênero nos termos das noções de natureza, controle e domínio doméstico nos compele a um tipo de leitura na qual tudo o que compete às mulheres é interpretado como reflexo de seu lugar subordinado na sociedade. Consequentemente, as mulheres aparecem nas análises como inevitavelmente "perdedoras": qualquer tipo de prática pode ser taxada de sexista, ou seja, como delegando uma posição inferior às mulheres.

Ao descolar o gênero das ideias de antagonismo e hierarquia (dominação), Overing (1986) propõe, então, o seu entendimento como diferença complementar e simétrica. Dessa forma, a autora abre a trilha para trabalhos que abordam este assunto descolado dos pressupostos ocidentais,

1 Tanto os Murphy como Janet Siskind - para quem a vida social baseava-se na troca de sexo por carne, entre homens e mulheres - recusaram uma caracterização das mulheres indígenas como submissas (Belaunde 2015). 
em torno das oposições público/doméstico e da superioridade da cultura em relação à natureza, que fundava, por exemplo, a formulação de Ortner (1974) de que a inferioridade universal das mulheres decorria de sua associação (também universal) ao domínio da natureza ${ }^{2}$. Autores como Luisa Belaunde (1994, 2001, 2005), Cecilia McCallum (1999, 2001), Cristiane Lasmar $(1996,2005,2008)$ e, de forma mais periférica em relação aos seus interesses principais, Peter Gow (1989) demonstraram a relevância do estudo das relações de gênero para a compreensão das socialidades ameríndias.

No caso das terras baixas sul-americanas, a questão do gênero articula-se necessariamente com a centralidade dos dispositivos de fabricação do corpo na constituição da pessoa, conforme desenvolvido nos trabalhos de Seeger et al. (1979), Viveiros de Castro $(1979,1996)$ e Tânia Stolze Lima (1996, 2002). Em consonância com essas abordagens acerca do corpo/pessoa, Belaunde e McCallum tomaram como objeto privilegiado de investigação a necessidade de fabricar corpos e capacidades produtivas generificados, isto é, masculinos ou femininos, e os mecanismos cotidianos e rituais para a inscrição apropriada desta diferença nos corpos.
Inspirado em algumas das questões colocadas por essas autoras, este artigo retoma um tema clássico para a discussão de gênero na América do Sul e alhures: o ritual - no caso, o Wayo 'at Kanã (ou, em português, Festa do Jacaré) - concebido como uma "festa de mulheres" pelos e pelas Karo-Arara, junto aos quais desenvolvo pesquisa desde 2010. Na descrição dessas festas (Otero dos Santos 2014, 2015), mostrei como uma variação entre socialidade feminina, masculina e de sexo cruzado marca todo o desenrolar do ritual e é determinante para a sua compreensão. Foi para entender esta festa e sua promoção a símbolo da cultura e do povo Karo-Arara (por meio de uma política cultural muito bem pensada pelo cacique e alguns moradores da aldeia Paygap) que me voltei para os estudos do gênero em etnologia.

Agora, volto à etnografia do Wayo 'at Kanã, tema central de minha tese de doutorado (Otero dos Santos 2015), guiada por duas novas apostas. Em primeiro lugar, acredito que, neste espaço-tempo, a agência feminina se faz mostrar em uma outra face, uma que é avessa a qualquer caracterização de domesticidade, interioridade ou consanguinidade, atribuições ordinárias para o universo feminino na etnologia das terras baixas (Descola 2001; McCallum 2001; Viveiros de Castro 2002a, 2002b).

2 A crítica à concepção de que a analogia mulher : natureza :: homem : cultura seria universal já havia sido feita por MacCormack e Strathern, na coletânea "Nature, culture and gender: a critique" (1980). Essa analogia é desmontada basicamente por duas razões: nem todas as sociedades trabalham com a oposição natureza/cultura (Strathern 2014); a cultura não é necessariamente superior à natureza (Gillison apud Overing 1986). É a reflexão dessas autoras que inspira o texto de Overing (1986). 
O que a Festa do Jacaré faz aparecer, quando lida do ponto de vista de uma outra festa com a qual mantém uma relação um tanto quanto especular, é uma alteridade imanente à posição feminina e certa capacidade predatória das mulheres.

Em segundo lugar, a análise do ritual possibilita, ainda, a abordagem de um tema pouco desenvolvido na etnologia das terras baixas sul-americanas: a relação entre gênero e perspectiva. Pretendo mostrar como é uma divergência de perspectivas entre homens e mulheres que enseja o Wayo 'at Kanã. Este texto é, assim, uma tentativa de pensar o gênero da perspectiva; de, desde os limites da minha etnografia, "pensar a perspectiva para os casos em que ela se liga aos sexos, ou seja, aos homens e às mulheres" (Lima 2005:322), como coloca Tânia S. Lima, em "Um peixe olhou para mim", um livro que, sendo sobre tantas faces da vida de um povo indígena amazônico, é também sobre gênero³.

\section{0 WAYO 'AT KANÃ}

Falantes de uma língua isolada da família Ramarama, do tronco Tupi, os Karo-Arara compõem uma população de cerca de 382 pessoas (Sesai 2014) ${ }^{4}$, distribuídas em três aldeias - Iterap (um conjunto de diversas aldeias menores),
Paygap e Cinco Irmãos - na Terra Indígena (TI) Igarapé Lourdes, situada no município de JiParaná, em Rondônia. Deslocam-se em grupos familiares pela bacia do rio Machado desde tempos imemoriais. Mesmo com um modo de vida marcado por andanças e pela abertura incessante de lugares, cujas transformações se fazem sentir desde que optaram por uma permanência mais duradoura em aldeias (a partir de 1985), sempre foram agricultores e produtores de bebida. A caça também é parte importante de sua economia e cosmologia.

Contam os velhos que, no tempo da maloca, sucedia-se um Wayo 'at Kanã nas ocasiões em que as pessoas desejavam comer jacaré e dançar. Wayo é a palavra para jacaré, 'at é o pronome possessivo da $3^{\text {a }}$ pessoa do singular e kanã, um termo para "coisa". Sebastião Kara'yã Péw, professor indígena licenciado em educação intercultural e um dos meus principais interlocutores, entende a expressão como significando "a hora e o lugar do jacaré". Em uma tradução livre, poderíamos falar em “evento do jacaré”. Também é possível referirse à festa pelo conjunto de suas ações: tomar

3 O livro de Lima é, para mim, uma fonte inesgotável de consulta. A maestria da etnógrafa e etnóloga soube amarrar os principais problemas da etnologia amazônica, sempre conduzida pela socialidade yudjá. Em diálogo com Lévi-Strauss, McCallum e Viveiros de Castro, os capítulos 6 e 7 oferecem uma reflexão sofisticada sobre gênero (e perspectiva), à qual pretendo voltar futuramente, para melhor dar conta de algumas das questões tratadas ao longo deste texto.

4 Informação enviada por correio eletrônico. 
chicha, na'mếk kap 'oa'; dançar, na'na; e matar vários jacarés, wayo iapia kanã. Wayo pa'xi, caldo de jacaré, tomado por todos ao final da festa, é outra forma de nomear o rito.

Estive presente em quatro edições da festa: duas realizadas em Paygap, em 2010 e 2012, e outras duas que tiveram lugar em Iterap, uma em 2011 e outra em 2016. Cada uma delas descortina diferentes movimentos, relações e efeitos. As festas karo-araras não são pautadas pela formalidade e estereotipia, geralmente tidas como características do ritual. O espaço-tempo da festa é altamente aberto ao improviso e à criatividade dos participantes.

É consenso que as festas de 2010 e 2016 foram um sucesso. Os participantes ficaram animados, wãw nãm, e, principalmente na festa de Paygap, belos, pättem, ou seja, enfeitados e bem vestidos. A alegria e a beleza são critérios fundamentais para aferir o êxito do ritual. Nas duas ocasiões, desenrolou-se o roteiro ritual mais completo que pude presenciar, que incluía a execução dos jacarés vivos. A descrição que se segue baseia-se nessas duas ocasiões ${ }^{6}$.

Em linhas gerais, o Wayo 'at Kanã, realizado sempre na estação seca (setembro), inicia-se com a captura de jacarés (da espécie jacaretinga) por homens designados pelo dono ou dona da festa. Os animais são mantidos vivos e amordaçados, amarrados a algum pedaço de tronco, na beira de um igarapé, na aldeia. Durante cerca de dois ou três dias, Cícero Xia Mót, o pajé mais forte, auxiliado por outros senhores mais velhos, também pajés, conduz os cantos e as danças que ocorrem durante o dia, mas principalmente à noite. Os pajés são quase sempre acompanhados por suas esposas. As danças são iniciadas por esse grupo e, aos poucos, homens e mulheres, em sua maioria jovens solteiros/as ou recém-casados/as, vão formando fileiras, de braços dados, ora separados por gênero, ora misturados. Durante esses dias, as pessoas tomam na'mếk kap, e compartilham refeições.

No último dia da festa, os pajés, acompanhados pelo dono ou pela dona da festa e por alguns homens, buscam os animais no rio para dançar com os participantes. Os homens adentram a aldeia, assoviando e batendo com pedaços de tronco de buriti no chão. Ambas as ações servem

5 Conhecida regionalmente como macaloba, esta bebida é feita de macaxeira, cará ou milho, sendo tomada em versão doce e, em cada vez mais raras ocasiões, fermentada. Somente nas festas de 2010 e 2016, foi servida a bebida azeda (em pouca quantidade, segundo os presentes).

6 Na edição de 2011, dois jacarés pequenos foram levados já mortos para a aldeia pelos caçadores, não havendo, portanto, a morte dos animais a pauladas pelas mulheres. Somente os homens velhos comeram o caldo do animal, servido no último dia da festa. Na festa de 2012, mistura de Wayo 'at Kanã e Encontro de Pajés, o animal também foi morto no momento da captura por um motorista do Conselho Indigenista Missionário (CIMI), que não sabia que o animal precisava ser levado vivo. Além disso, tratava-se de um jacaré-açu, e não de um jacaretinga, a espécie apropriada para o ritual. Apesar de o jacaré-açu ser um animal interdito para consumo humano, a maioria dos participantes tomou a sopa preparada ao final da festa. Analiso esse episódio alhures (Otero dos Santos 2015). 
para espantar wayo 'at ximĩt, o espírito do jacaré. $\mathrm{O}$ canto e a dança que se seguem acontecem no terreiro do dono ou da dona festa. Antigamente, dançava-se dentro de uma maloca construída especialmente para a ocasião.

A sequência dos movimentos e as coreografias alternam-se, mas elas incluem uma variação entre os momentos em que homens e mulheres dançam separadamente e as danças em que os sexos se misturam. Uma dança feminina antecede a execução dos jacarés. Na festa de 2010, organizada por Pedro Agamenon, cacique da aldeia Paygap, após serem retirados do igarapé pelos homens, os dois jacarés apanhados para o ritual foram entregues às mulheres, que dançaram com eles nos braços, em fila, umas ao lado das outras, de braços dados. $\mathrm{O}$ dono da festa juntou-se às mulheres e, aos poucos, os homens foram se incorporando à dança, formando uma fila própria. Alguns, principalmente os mais jovens, misturaram-se às mulheres, a maioria jovens solteiras ou recémcasadas. As mulheres mais idosas, já avós, também compunham o corpo de dançarinas. Os jacarés foram, então, carregados nos braços por uma dupla, geralmente formada por pessoas do mesmo sexo, que dançava com os animais por um curto período e, em seguida, passava-os adiante para a próxima dupla. No caso de duos de sexo cruzado, seus componentes não eram da mesma geração ${ }^{7}$.

A festa de 2016 foi realizada como comemoração da defesa do trabalho de conclusão do curso de Licenciatura Intercultural Indígena, da Universidade Federal de Rondônia, de Marli Pem, professora em Iterap e irmã de Kara'yã Péw. O trabalho era sobre a Festa do Jacaré, e a defesa aconteceu na aldeia, seguida de um Wayo 'at Kanã comandado por Marli, com o apoio de sua mãe, de seu cunhado e sua cunhada. O único jacaré capturado, após ser carregado pelo filho de Cícero em direção à casa de Pem, foi entregue a Alicate, cunhado de Marli, em frente à casa dela. Neste momento bem breve, só os homens e a esposa de um dos pajés dançaram. Alguns minutos depois, o jacaré foi colocado no chão do terreiro que une outras casas da aldeia. Nessa circunstância, era possível visualizar três grupos dançando separadamente: os pajés, os homens jovens e as mulheres jovens. Em seguida, três senhoras se juntaram ao grupo, dançando em trio. As mulheres de diferentes idades foram, então, se juntando, fazendo uma roda, com os pajés Benedito e Manichula, e o jacaré no centro.

$7 \mathrm{Na}$ festa de Paygap, a exceção a esse padrão ficou por conta de um casal de não índios, formado por uma missionária do CIMI, que trabalhava com os Karo-Arara, e por seu companheiro. Em seguida ao sacrifício dos jacarés, este casal protagonizou uma etapa imprevista do ritual: a celebração do seu casamento. Mais adiante, retomo esse acontecimento e mostro como ele passa a compor a interpretação nativa do ritual. 
Depois de um intervalo para o almoço, o jacaré permaneceu nos braços dos homens enquanto os participantes dançavam. Um trio masculino segurava os animais. A dona da festa serviu na'mếk kap para os homens que dançavam, para algumas mulheres e vários brancos presentes na festa. Em seguida, as mulheres, de todas as idades, formaram uma fila, com Marli e mais duas segurando o jacaré. Sem nenhuma paramentação (com exceção de um colar), Joana, esposa do pajé Cícero, comandou esse momento, cantando, dançando e tocando um maracá. Os homens apenas assistiam.

Em seguida à dança feminina, Cícero escolheu as mulheres que executariam os animais. Em Iterap, uma mulher para um jacaré. Em Paygap, foram duas mulheres para dois jacarés. Cada qual se posicionou ao lado de sua vítima e, ao sinal do xamã, no ápice da festa, desferiram sobre ela golpes de pau. Mortas as presas, começaram a ecoar pelo terreiro os assovios, executados pelos homens, cujo objetivo era avisar o kopât - termo cuja tradução mais comum é "bicho" e que designa, entre outras coisas, o espírito auxiliar do xamã - sobre a presença do animal para que protegesse a todos dos perigos de wayo 'at ximiit, o espírito do jacaré.
As matadoras foram, então, servidas de bebida azeda em uma quantidade deliberadamente excessiva, sendo incentivadas a tomar a bebida de uma só vez. Os recipientes foram enchidos novamente. Na festa realizada em Paygap, em 2010 , as duas mulheres vomitaram seguidamente para conseguir tomar toda a bebida. Ainda assim, a julgar pelos comentários posteriores, não beberam a quantidade que seria correta (ao menos, em outro contexto), porque se tratava ali, como insistiu Nakyt, professor e um dos mais envolvidos na organização e condução da festa, marido de uma das matadoras, de uma apresentação $0^{8}$.

Na última noite da festa, os jacarés são consumidos em caldo (preferencialmente de milho), por todos, com exceção de crianças menores de um ano, que não devem nem participar do ritual, sob o risco de sentirem os efeitos da alma dos jacarés. $\mathrm{Na}$ festa de 2010, após a ingestão do caldo, as mulheres, principalmente as jovens e mães que ainda não têm filhos jovens, dançaram juntas no baile final.

Há uma concordância geral sobre o sentido do ritual, enunciado por todos os homens e mulheres adultos com quem conversei: as mulheres matam os jacarés para descontar a raiva que sentem dos filhos

8 Essa festa foi realizada como uma das atividades de um projeto da aldeia Paygap aprovado no âmbito do programa Projetos Demonstrativos dos Povos Indígenas do Ministério do Meio Ambiente (PDPI-MMA), em 2009. A partir de então e do compromisso firmado entre Pedro e alguns moradores da aldeia Iterap, o Wayo 'at Kanã adquiriu periodicidade anual, sendo realizado a cada ano em uma das aldeias. O projeto do PDPI é uma motivação extra para se empreender o Wayo 'at Kanã, pois a festa não é um ritual que se perdeu no tempo, embora não viesse sendo realizado com tanta regularidade nos anos anteriores. A novidade trazida pelo projeto é adicionar ao ritual um componente étnico, na medida em que ele passa a ser um dos símbolos do povo Karo-Arara. 
e mostrar que têm coragem suficiente não somente para bater em suas crianças, mas para matar estes animais considerados bichos brabos, e também para beber até cair. Ou, segundo interpretação equivalente, para tirarem a raiva que sentem (pakát) e, consequentemente, não agredirem seus filhos. Estas são as ideias associadas à execução do animal por mulheres consideradas pewíup, brabas.

\section{0 GÊNERO DOS RITUAIS}

O Wayo 'at Kanã é caracterizado pelos KaroArara como uma "festa de mulheres", em oposição a um ritual considerado masculino, atualmente em desuso, em que o animal sacrificado é um xerimbabo do dono da festa, prototipicamente, um porco-do-mato ${ }^{9}$, que deve ser executado por homens da aldeia convidada. Como escutei de um interlocutor, "a mulherada fazia Festa do Jacaré. Fazia macaloba e matava o jacaré. Homem também fazia festa. Matava porco". Nas palavras de outro senhor, "homem mata porco e dança com porco; mulher mata jacaré e dança com jacaré".

Se os homens matam um animal doméstico, maxa' ût wit - no cotidiano associado ao universo feminino, são, em geral, as mulheres que alimentam e cuidam de um xerimbabo como se fosse um filho -, as mulheres executam um animal selvagem, possível presa dos homens. Digo possível porque wayo pûk (jacaretinga), a presa que enseja o ritual, é um animal com um status particular: pode ser makúy, presa, mas também pode ser kopât, espírito. Ainda que a espécie não seja uma caça totalmente interdita, há algumas ressalvas em torno de sua captura e ingestão. Abundam histórias de doenças e mortes causadas por wayo 'at ximĩt (espírito do jacaré). Mulheres com filhos pequenos são particularmente suscetíveis às ações maléficas do animal. Dirigir o olhar para o caçador que retorna do mato faria mal para o bebê ou mesmo para ela ${ }^{10}$. Além disso, não se deve reservar a carne para consumo posterior. É necessário consumila de uma só vez. Caso contrário, a criança fica gelada e adoece. Aplicar uma massagem no corpo dela com os utensílios destinados para matar e cozinhar o animal é a forma de curá-la.

A Festa do Jacaré e a Festa de Xerimbabo desenrolam-se em torno de animais cujo estatuto é vacilante, e que, fora do contexto cerimonial, dificilmente aparecem como presas: um animal de

$9 \mathrm{O}$ animal morto ritualmente podia ser um veado, um nambu, um macaco ou um caititu, mas, nas descrições concretas que obtive, as pessoas referiam-se ao yate, queixada. Assim, refiro-me a esse ritual como Yate 'at Kanã, ou pelo nome genérico de Festa de Xerimbabo.

10 Antigamente, os homens tocavam flautas de taquara em duos e dançavam cobertos da cabeça aos pés por uma vestimenta de palha, que impedia que fossem reconhecidos. As mulheres não deveriam ver os flautistas dançarinos sob suas vestes de palha. 
criação e um animal que é uma versão reduzida de wayo kût (jacaré-açu), este indubitavelmente um kopât e, por isso, não comestível. As mulheres criam os animais que serão mortos pelos homens. Os homens capturam animais que serão executados pelas mulheres.

As vítimas animais são termos que operam substituições. No caso das festas de xerimbabo, o animal de criação (um parente, do ponto de vista de seu dono) substitui o dono, o qual encontrase na posição de inimigo em relação ao matador, conforme demonstra Dal Poz (1991) para os rituais cinta-larga de mesmo enredo. No Wayo 'at Kanã, o jacaré substitui o filho da matadora do ponto de vista de homens e mulheres. Neste sentido, ocupando a posição de matadores/as, os homens afinizam animais (domésticos) aparentados pelas mulheres e as mulheres consanguinizam presas (selvagens) capturadas pelos homens. Ambos deveriam tomar chicha até cair após executarem os animais, embora nos Wayo 'at Kanã dos quais tomei parte, a quantidade ingerida tenha sido considerada pequena pelas pessoas.

A última festa com animal de criação de que tive notícias foi realizada em Iterap há mais de trinta anos. Na época, alguns moradores criavam caprinos e o animal sacrificado foi uma cabra. Geralmente apanhado após uma caçada em que a mãe foi morta, o maxa'út wit era criado desde filhote. Quando ele estava gordo e crescido, o dono convidava as pessoas para a festa. Algumas dessas festas parecem ter tido os Gavião e Zoró como convidados, mas o mais comum era chamar os moradores de outras malocas karo-araras.

Há controvérsias sobre quem matava o xerimbabo. Segundo Cícero, era o dono da festa que escolhia entre os convidados o homem que dispararia a primeira flecha. Já conforme Nakyt, professor em Paygap, o matador era o primeiro que acertasse o animal no momento em que o conjunto de homens lançava suas flechas. Independentemente de como era determinado, ao matador era destinada uma quantidade exorbitante de bebida. Uma folha era ingerida para provocar o vômito, facilitando o consumo desmedido. $\mathrm{O}$ matador costumava passar mal e ficar prostrado. Nas palavras de Nakyt, ele "nem participava da festa”, o que revela o seu status particular. Os demais participantes também tomavam a bebida, porém, em menor quantidade, sem o exagero imposto ao matador. Bebiam o suficiente para ficar animados; bebia-se, nas palavras do professor, "a quantidade certa". Só o matador tomava muito "para descontar aquele bicho que matou".

Os convidados deixavam para o dono todos os seus colares e flechas, "voltavam sem nada". A doação de artesanato em retribuição à bebida e à comida ofertada pelo dono da festa, também é 
registrada por Dal Poz (1991) para a festa cintalarga. $\mathrm{O}$ autor descreve mais de uma dezena de rituais, com duração que varia entre três e vinte dias. Apenas em duas ocasiões, o sacrifício animal compôs o script, antecedendo a dança final. O matador é o convidado de honra - o primeiro a ser chamado para participar do ritual - que, via de regra, retribui o convite, realizando uma festa em sua aldeia no ano seguinte, o que "implica, de partida, uma relação recíproca entre dois ou mais grupos locais” (Dal Poz 1991:201).

Cabe ao anfitrião cinta-larga oferecer chicha e carne. Em troca, os convidados "sofrem" dançando e cantando. Ao final, deixam colares e flechas para $o(s)$ dono(s) da festa. A principal relação que a festa cinta-larga coloca em tela é aquela entre convidados e anfitriões, enquanto metáfora da guerra:

a festa, de várias maneiras, situa-
se no contexto da guerra, real ou
imaginária, confrontando dois grupos
opostos: num caso, são os guerreiros
que partem; no outro, os 'inimigos',
são os convidados. E, neste cenário, a
festa ritualiza relações de hostilidade
e reciprocidade entre eles, enquanto
condição necessária de sua existência
social (Dal Poz 1991:203).

Os Cinta-Larga designam os convidados como mâmarey, "os outros", o mesmo termo para uma relação virtual de afinidade. Como os inimigos, os convidados vêm de fora. Dal Poz mostra como, de início, os visitantes agem exatamente como inimigos potenciais. Eles acampam silenciosamente nos arredores da aldeia, adentrando-a durante a noite de forma barulhenta e encenando uma performance guerreira. Gritam, empunham seus arcos e atiram flechas no pátio. Tocando suas flautas, entram agressivamente nas casas. A intenção declarada é assustar o dono da festa e os moradores da aldeia, encenando relações hostis, que, "no entanto, contrasta nitidamente com as relações amistosas que, ao fim, irão prevalecer" (Dal Poz 1991:208). O que o ritual faz é transformar uma inimizade virtual em hospitalidade; ou, em outra linguagem, a "afinidade potencial" em aliança.

O Wayo 'at Kanã e o Yate 'at Kanã se opõem e se complementam por meio das molduras (cf. Lévi-Strauss 2004a) e dos modos relacionais que os estruturam. Como as falas de meus interlocutores permitem entrever e a descrição de Dal Poz (1991) deixa evidente para o caso cinta-larga, a armação do ritual do xerimbabo é a afinidade expressa por meio da relação entre convidados e anfitriões (especialmente, homens). Em contrapartida, a armação do Wayo 'at Kanã é, como mostrarei em seguida, a conjugalidade expressa por meio da relação entre os sexos. Os KaroArara fazem das relações entre os gêneros e das relações entre "nós" e "outros" contextos separados em dois rituais complementares. 
Se essas duas molduras relacionais costumam aparecer alhures juntas em um único ritual, especialmente naqueles estruturados na oposição entre os sexos - como os rituais pano de visita matsés, analisados por Matos (2017), ou o Kachanawa dos Kaxinawa (McCallum 2001) -, no caso aqui, os temas do gênero e da afinidade parecem se desprender em dois espaços-tempos separados ${ }^{11}$.

As relações que emergem no Wayo 'at Kanã embaralham as posições entre convidados e anfitriões, na medida em que misturam pessoas oriundas das duas aldeias. Os convidados são referidos como tap páy, "parentes outros". Desconheço a existência de um nome para anfitrião, mas o dono da festa pode ser chamado de nana kanã koa, "dono da dança", o que aponta para uma diferença em relação ao ritual cinta-larga: é obrigação dos anfitriões paramentar-se e dançar. Diferentemente do que se passa na Festa do Xerimbabo, o antagonismo entre visitantes e anfitriões é, como veremos, neutralizado por uma associação das pessoas por gênero. Três configurações sociais destacam-se ao longo da festa. Por um lado, tem-se uma socialidade masculina associada ora à senioridade, representada pelo grupo de pajés e velhos que comandam a festa, ora pelos homens que dançam, sejam jovens ou adultos. Por outro lado, precipita-se uma socialidade feminina constituída por mulheres de diferentes aldeias e idades. Em alguns momentos, homens e mulheres, principalmente jovens solteiros e solteiras, dançam misturados em fila.

Na festa realizada em Paygap, em 2010, ao longo dos três dias, além de iniciarem e conduzirem todas as etapas do ritual, o cacique e os pajés permaneceram juntos o tempo inteiro, formando um bloco que se destacava visualmente justamente por seu caráter monolítico e pelos enfeites que ostentavam lanças de buriti, cocares e flechas. Em vários momentos, somente esse grupo dançou. As mulheres dos pajés, com exceção de um momento em que apenas seus maridos dançaram em círculo, trocando de lugar uns com os outros, estiveram praticamente o tempo inteiro junto aos seus esposos. Significativamente, portavam pouco ou nenhum enfeite, como que a exibir em seus corpos, por contraste, a visibilidade de seus maridos. Estaria a conjugalidade sendo eclipsada - a esposa do cacique sequer

11 Com isso, não pretendo negar que, possivelmente, todo ritual indígena estabelece uma distinção do tipo nós e outros $e$ faz da distinção entre os gêneros matéria fundamental de parte de suas ações e alusões simbólicas, mas frisar que as perspectivas relevantes no Wayo 'at Kanã são as de homens e mulheres. No Yate 'at Kanã, as perspectivas que importam são as dos anfitriões e convidados. As perspectivas acionadas pelos diferentes rituais são pensadas aqui, principalmente, em relação às vítimas animais de cada um deles. 
tomava parte deste grupo - para dar lugar a uma socialidade masculina?

Os momentos da socialidade feminina são aqueles em que as mulheres dançam juntas, especialmente no último dia da festa quando elas dançam com o jacaré antes da execução dos animais. Na festa realizada em Paygap, em 2010, um baile noturno com as mulheres dançando sozinhas, comandadas por Marisa, uma das matadoras e filha do cacique da aldeia, encerrou a festa. Assim como os movimentos que envolvem a socialidade masculina, as danças misturam indiscriminadamente anfitriãs e convidadas. $\mathrm{Na}$ produção da bebida consumida durante a festa, mulheres de diferentes procedências também se misturam, configurando grupos formados segundo o parentesco.

\section{PARENTES INCONSTANTES: RAIVA, MATERNIDADE E CONJUGALIDADE}

Alguns homens adultos sempre insistiram que homens também poderiam matar os jacarés, embora tenham dito só ter visto mulheres executando tal ação. Maria ‘Ora Yõ, uma senhora de Iterap, também corrobora essa tese: maridos que batem em suas esposas podem matar o animal. Em conversa com o pajé Cícero e sua esposa Joana, o pajé estabelece uma terceira possibilidade para o sacrifício dos animais:
Péw: Ma'pây ña möm ahyâ wayo win mây mãm?

Antigamente, eram só as mulheres que matavam?

Cícero: Ahã [concordando]

Joana: Nãn to' wa tabet karo yaro'mây toba karo wat owé kokõm.

Isso é para ver se a mulher tem coragem de matar o bicho, assim como bate nos filhos.

Cícero: Kõyâ okay ma' wut wia ã to' wa ña kõam.

Isso é para ver se elas têm coragem de bater nos homens também.

Joana [em português]: Para ver se a mulher tem coragem de matar criança mesmo, por isso que mandaram matar o jacaré.

Cícero: I'xu mãm kây koam

Gente grande também.

Kõm ahyã okay omèm mãm

É para ver se ela tem coragem de matar o próprio marido.

Uma série de substituições encadeia-se: jacaré : filho : marido: esposa. Mães que batem em suas crianças ou seus maridos e homens que batem em suas esposas são pewíup, brabos. Mata-se o jacaré para demonstrar coragem e descontar a raiva, pakán, que se sente dos parentes. Em todos os casos previstos, o afeto é dirigido a alguém vinculado a um grupo de relações estabelecido pela conjugalidade: um marido, uma esposa ou um/a filho/a, pessoas que deveriam estar absolutamente fora do raio de alcance desse afeto. A raiva desmedida - um sentimento primordialmente vinculado à guerra e canalizado para o inimigo - é o afeto obviado pelo ritual.

Sentir raiva é socialmente aceitável quando se aprende a controlar tal sentimento. Aquele que sente raiva momentaneamente não necessariamente irá 
agir, mas aquele que é pewíup "é como ameko, a onça brava, mata mesmo", explicou-me Kara'yã Péw. A principal analogia oferecida por meus interlocutores para explicar o significado de pewíup é justamente com a onça; se é pewíup, como ela o é. O termo denota uma disposição para atacar e matar um oponente, e também pode ser usado para se referir a um inimigo ou ao próprio matador karoarara nos tempos em que empreendiam guerras.

A raiva é também uma emoção muito comum entre os mortos do sexo masculino. $\mathrm{O}$ afeto aparece tanto direcionado às esposas, como enquanto algo difuso, não endereçado a um objeto definido, ou melhor, direcionado a toda comunidade de parentes. Histórias sobre o desejo dos mortos de acabarem com o mundo quando sua alma chega ao céu são relativamente ordinárias. Alguns dizem, ainda em vida, que irão mandar muita chuva quando estiverem no firmamento, alagando toda a terra. Significativamente, estas narrativas sempre têm como sujeito principal uma pessoa do sexo masculino cujo temperamento em vida era considerado violento ${ }^{12}$.É sempre trabalho do xamã aplacar a raiva do homem brabo ou, talvez, de ameko pewíup, uma vez que é onça que as pessoas viram depois de mortas.

Não há consenso se a alma de todas as pessoas vira onça após a morte ou se somente daquelas consideradas brabas. No caminho para o céu, antes da metamorfose em onça imposta pelas flechas de Toto Néw, o grande demiurgo karo-arara - para quem as ferroadas de marimbondo lançadas na alma do morto são flechas -,é preciso atravessar várias vezes um cipó fino que faz as vezes de ponte, conectando as margens de um grande rio, e é balançado pela divindade. Aqueles que não têm habilidade para tanto caem no rio e viram jacaré. Os demais seguem o caminho rumo à transformação em onça.

Os eclipses são índices da ira de um morto: eles assinalam a queima do céu provocada por um finado com a intenção deliberada de acabar com o mundo e com seus parentes. Métraux (1979:35) faz menção a mitos tupinambá e guarani que explicam o eclipse como uma perseguição da lua (e eventualmente do sol) por um jaguar. A devoração da lua por este animal seria a causa dos eclipses. Um morto transformado em onça é, no caso karoarara, o causador dos eclipses.

Quando uma pessoa morre, ao chegar no céu, sua ximĩt, pode dizer para Toto Néw que não tem mais gente na terra. Toto Néw poderia, assim, decidir acabar com o mundo. Mulungu, o atual cacique de Iterap, contou-me a seguinte história:

12 Os três homens que parecem ter causado maiores problemas aos vivos possivelmente foram vítimas de assassinato. Podemos especular se a raiva sentida pelo morto teria alguma relação com as circunstâncias da morte, como se passa entre os Gavião. Quando um Gavião morre, troveja e é possível escutar a zoada das abelhas no céu. Os mortos sempre tentam atacar Goihanguir, o espírito do Arco-íris branco. As pessoas que foram assassinadas costumam ser as mais estrondosas em sua fúria contra o espírito (Mindlin et al. 2001:69). 
o pai de Irineu, ele era $a^{\prime}$ go $a^{\prime}$ pât (pajé). Ele salvou o mundo. Escureceu tudo, tinha só um tracinho de luz no céu. Ité Maranhão pegou o arco e foi conversar com seu mamât [espírito auxiliar do pajé]. Ele conversou lá e Toto Néw decidiu não acabar com o mundo.

Para deter a ira dos mortos e o fim do mundo, ao pajé sempre se colocam duas alternativas: conversar e acalmar os espíritos ou regenerar a espécie a partir de uma única relação sexual com sua filha.

No passado, quando alguém ousava pronunciar o nome de um morto, este arremessava o dente para furar a cabeça do enunciador, matando-o. As pessoas evitam pronunciar o nome dos mortos, preferindo referir-se a eles pela expressão 'at topaba át, "aquele que morreu", ou ga topaba $g a$, "aquela que morreu", ou, em português, finado(a). É significativo que o instrumento do assassínio daquele que ousa fazê-lo seja justamente um dente, $y \tilde{a} y$, a marca do predador e, na Amazônia indígena, particularmente, da onça. Mortos pewíup aparecem como pura ferocidade, voltando-se para seus antigos parentes, especialmente suas esposas.

Mulheres que agridem seus filhos, maridos que são violentos com suas esposas e mulheres que podem vir a assassinar seus esposos comportam-se como inimigos, mortos ou onça. A raiva instaura a alteridade não domesticada no seio da mais restrita referência possível de um tap (grupo de parentes ou o pessoal de alguém): um homem, uma mulher e seus filhos. Como uma fagulha, esse afeto coloca em risco todo o trabalho da produção de pessoas efetuado no cotidiano por meio do convívio familiar, do cuidado mútuo, das práticas de comensalidade e da produção econômica conjunta. Mesmo a família conjugal é inconstante e precisa de mecanismos cotidianos e rituais para se estabilizar.

É fundamental notar que o jacaré é filho da mulher (mas não do homem) para homens e mulheres. O conjunto de analogias não prevê que o animal possa substituir um filho para um homem violento. $\mathrm{Na}$ verdade, é bastante infrequente que se atribua aos pais atitudes agressivas com suas crianças. O mesmo não se pode dizer das mães, a quem não raro são imputadas ações, principalmente ameaças verbais - vinculadas a uma ideia de brutalidade e falta de zelo -, que destoam da caracterização generalizada do cuidado das crianças em grupos indígenas como totalmente refratário à violência. Entre os Karo-Arara, porém, mães são acusadas de bater em suas crianças, o que é motivo de preocupação, pois a alma da criança pode fugir quando ela apanha. Jamais observei qualquer ato de violência desmedida infligido pelas mães aos seus filhos. Que pressupostos sustentam, portanto, esse tipo de afirmação e que dão ensejo ao ritual? Por que o jacaré é um filho para uma mulher e não para um homem? 


\section{MULHERES, JACARÉS E CASAMENTO: OBVIANDO A PREDAÇÃO FEMININA}

Uma afirmação do pajé Cícero sempre me intrigou por ser desconhecida por todos os meus interlocutores, com exceção de Paulo, um senhor morador de Itarap. Quando perguntei a ele se são sempre as mulheres que matam o jacaré na festa, o pajé confirmou: "é verdade, pra fazer casamento". Segundo me disse, "os antigos comiam o jacaré nas festas. Nos casamentos. No casamento, para viver junto. Se fizer casamento sem jacaré, a mulher fica separando do marido".

De algum modo, essa interpretação do ritual pode estar relacionada a um evento extraordinário que teve lugar no Wayo 'at Kanã realizado em Paygap em 2010: o casamento da missionária do CIMI, que então trabalhava com os Karo-Arara, e seu namorado, celebrado logo após a execução dos animais. A missionária e o companheiro foram pegos de surpresa e cercados por um grupo de pessoas. Alicate, cacique de Iterap à época, conduziu a rápida cerimônia. Disse, em português, que agora eles estavam casados, que não poderiam mais se separar e perguntou mais de uma vez se eles queriam mesmo ficar juntos. Uma outra missionária do CIMI também abençoou o casamento; outros homens também falaram, sendo que um deles, de Iterap, puxou uma oração. Duas alianças de coco de tucumã, doadas na hora por uma mulher, foram colocadas no dedo anelar direito dos "noivos", conforme o costume católico. A seriedade dos participantes neste momento contrastava com a alegria e descontração que deram a tônica do ritual, com exceção do momento do sacrifício animal. Algumas associações entre Festa do Jacaré e casamento foram sugeridas após esse episódio.

Creio que a relação entre jacaré e casamento é melhor compreendida se considerarmos o último menos como ponto de mudança de um estado ("civil") para outro do que como desdobramento temporal de uma condição. É preciso matar o animal para garantir a duração da relação conjugal. No contexto xamânico, o que garante essa duração é a duplicação das almas realizada por Cícero. Toda pessoa karo-arara possui, quando viva, uma cópia da alma (ximĩt) vivendo no céu e sendo zelada pelo pajé. Antigamente, quando as pessoas casavam na terra, o pajé fazia uma cópia da ximĩt de cada um dos cônjuges para que eles nunca se separassem.

Isso acontece depois que Cícero, ou seus espíritos auxiliares, copia(m) a alma com uma cabacinha, que funciona aos moldes de uma máquina fotográfica. Em geral, esta cópia é designada pelo termo xáp. Esta é também a palavra para imagem, fotografia e para árvores ou plantas que dão frutos ou alimentos; agaya xápé o cacaueiro e nãya xáp, o pé de milho, por exemplo. Xápé, a partir de então, zelada pelo pajé. Quando 
buscava compreender o que vinha a ser esta cópia produzida por Cícero, notadamente, as pessoas costumavam me dizer duas coisas: i) xáp casa no céu e constitui uma família; ii) antigamente, quando as pessoas casavam na terra, o pajé fazia uma cópia da ximĩt de cada um dos cônjuges para que eles nunca se separassem.

Espirituosos e piadistas, os Karo-Arara frequentemente se mostram sérios quando o assunto é um casamento recente, uma separação ou acontecimentos que envolvem abertamente uma relação matrimonial que está em construção ou em ruínas. Os casamentos costumavam ser arranjados pelos pais ou avós, às vezes logo que uma menina nascia. Ainda hoje acontecem matrimônios às expensas do desejo de um dos cônjuges, porém são menos comuns. Histórias sobre mulheres que se rebelaram contra a imposição de determinado parceiro são relativamente ordinárias. Algumas escaparam da decisão, outras resignaram-se.

O início de um casamento é sempre muito tenso. Há uma disputa por parte das famílias pelo casal, que envolve fofocas, acusações de que o filho ou filha passam fome na casa dos sogros e muita incerteza quanto ao futuro do matrimônio. A vida de um jovem casal é permeada por tensões porque os parentes exercem pressão sobre os cônjuges e seus familiares, com o objetivo de reter o casal em sua aldeia ou seção residencial. Há muitas tentativas de união que se desfazem logo no começo. As pessoas contam, e eu mesma presenciei, uniões de uma semana ou um mês. Depois que o casal tem filhos, as separações são mais raras, mas, ainda assim, podem ocorrer. Jamais escutei alguém separado se assumir como o agente do abandono. É sempre o outro que rompe o relacionamento.

Um homem e uma mulher que iniciam seu próprio tap estão dando continuidade ao processo de produção de pessoas, mas também retirando de outra unidade familiar um de seus membros. Em regimes predominantemente virilocais, caso dos meus anfitriões, a mulher deixa para trás sua família ou, pelo menos, enfraquece os laços com seus parentes ${ }^{13}$. A afinidade da esposa é amenizada com os anos de convivência e com a geração de filhos, que acabam por constituir um novo tap. Todavia, ao longo desse processo, a porção afim do cônjuge sempre pode vir à tona. A raiva da mãe dirigida a seu filho é um índice de sua alteridade. Ao expressar raiva por seu marido ou filhos, a mãe/esposa comporta-se como uma estrangeira. O Wayo 'at Kanã visa a obviar esse afeto/afecção. Por meio do assassínio dos jacarés e da ingestão imoderada de bebida, a afecção onça das mulheres

13 Note que a disputa em torno do casal evidencia a abertura do sistema no que tange à regra de residência. Como a virilocalidade está longe de ser uma prescrição intransponível, os parentes competem pelo casal. 
é, simultaneamente, neutralizada e realizada.

Ao dizer que a presença de jacarés garante o engajamento da esposa na relação conjugal, o rito inverte o papel dessa espécie enquanto amante de uma mulher casada segundo uma série de mitos sul-americanos analisados por Lévi-Strauss (2004b), em “Do mel às cinzas". Nesse conjunto, o jacaré aparece como um dos termos do grupo dos animais sedutores, posição que é também ocupada, em outras narrativas míticas, pela anta, pela cobra, pela preguiça e pelo jaguar. Esses animais, além de sedutores, são caracterizados pelo autor como "malfeitores", em oposição a personagens "benfeitores", estes quase sempre associados à origem do mel e das bebidas açucaradas. Enquanto estes benfeitores ou benfeitoras, que ofertam a um povo um alimento valorizado, são descritos como pudicos e reservados, o jacaré e os demais sedutores sexuais não são provedores, mas sim consumidores, gulosos, ladrões, sendo associados ao adultério.

Os sedutores são evocados por suas amantes para a união sexual de duas formas: ora chamados pelo nome próprio, ora por meio de sons percutidos (assobiando ou batendo em uma madeira ou cabaça). Os benfeitores, por sua vez, para que se mantenham unidos ao povo beneficiado e sigam provendo, não podem jamais ser evocados dessa forma, não sendo possível pronunciar seus nomes. Lévi-Strauss (2004b) também traça a diferenciação entre essas duas posições, caracterizando-os como sedutores sexuais (o grupo do jacaré) em oposição a sedutores alimentares (os benfeitores, em muitos casos, uma abelha).

No mito karo-arara que tem o jacaré como personagem central, uma mulher (ou menina, a depender da versão) que caminhava junto à beira de um pequeno igarapé é atraída pela imitação do canto de õm õm, um marreco, reproduzido pelo Jacaré. Na versão narrada por Maria 'Ora Yõ e seu esposo Dutra, a menina distrai-se arremessando um pedaço de pau na direção do canto de õm õm, uma espécie que nunca se pode ver, somente escutar, e que anda sempre junto ao jacaré. $\mathrm{Na}$ verdade, era o Jacaré que estava a imitar a ave para atrair a moça. Ela lançava os pedaços de pau em direção ao canto da ave, acreditando estar em terra firme. Quando, finalmente, decide parar e olhar para trás com o intuito de iniciar seu retorno, todo o caminho havia se transformado em água e a menina percebe que está no meio de um rio. Ela, então, pede ao Jacaré que a atravesse, desejo que não é atendido imediatamente. Primeiro, ele passa vários dias com ela no fundo do rio, conversando e lhe mostrando a sua casa - o que aparece como rio para as pessoas, é uma grande maloca para o Jacaré e o pajé. Jacaré deu muita miçanga para a menina - os ovos dele eram miçanga para ela. Ao final da jornada, ele disse à garota: "depois não vai 
dizer que eu sou fedido e minha catinga ficou em você. Vou te deixar em terra e você pedirá à sua mãe que traga linha para fazer o meu colar”. A menina, porém, não se conteve e falou: "totó (vovô), você passou a sua catinga para mim”. Ela volta para sua aldeia e alguns dias depois vai banharse no rio com outras meninas. Jacaré procura por ela, tateando os pés de todas as moças embaixo da água. Quando reconhece os pés dela, a come.

É com um som percutido - provocado pelo arremesso de gravetos - que a menina "chama" o Jacaré. Embora o mito não expresse uma intenção declarada dela de manter relações sexuais com o animal, seu passeio pelas profundezas do rio, o pedido de linha feito à garota pelo Jacaré e o cheiro que ele deixa nela são indícios da função sedutor do Jacaré na mitologia karo-arara ${ }^{14}$.

Ainda segundo Lévi-Strauss (2004b), essas narrativas de sedução e adultério que envolvem os jacarés e afins podem estar, frequentemente, associadas à origem das amazonas e à separação dos sexos, onde a união das mulheres a esses animais representa sua união à natureza. E, enquanto o jacaré come sexualmente sua amante, pode ser por ela comido no sentido alimentar, em uma relação que deflagra seu destino aquático: após ser comido, ele é jogado na água. No mito karo-arara, o jacaré ocupa as posições de predador sexual e alimentar.

As mulheres contam que não se deve banhar no rio quando se está menstruada, sob o risco de atrair e ser comida pelo jacaré. Antigamente, durante o período de reclusão da menina que tinha suas primeiras regras, ela não deveria aproximar-se do rio. Caso o fizesse, engravidaria. Ainda que meus interlocutores não o explicitem, talvez possamos supor que é o jacaré (e outros seres aquáticos) quem engravidaria a menina. Vale mencionar que uma de minhas principais interlocutoras foi contundente ao afirmar que manter relações sexuais durante o período menstrual ocasiona uma gestação.

A festa transforma justamente um predador sexual/alimentar em presa alimentar. Suspeito ser esse deslocamento que inspira a associação de Cícero e Paulo entre a duração do matrimônio e o jacaré. A porção sedutora e predadora do Jacaré é extirpada para fazê-lo aparecer enquanto presa, makûy, o que possibilita que os casamentos entre humanos perdurem. $\mathrm{O}$ rito transforma o amante predador em comida a ser desfrutada por homens e mulheres de todas as idades, logrando uma separação clara entre humanos e não humanos, ao impedir que as mulheres se identifiquem a esses últimos. É, como diria Lévi-Strauss, uma negação da união com a natureza. 


\section{AGÊNCIA, GÊNERO E PERSPECTIVA}

O Wayo 'at Kanã faz das matadoras vítimas da embriaguez induzida pelos homens, pois é por eles que elas são servidas após executarem os animais. Os homens dizem que as mulheres matam o jacaré para "ver se elas têm coragem de verdade". A coragem é requerida tanto para matar o animal como para beber uma quantidade exagerada de chicha fermentada. Os mais jovens muitas vezes afirmavam que a mulher executa os jacarés "para tomar macaloba", enxergando na vingança (e na alegria) o motor do ritual. A ingestão da bebida é para descontar o ato de matar: é uma vingança dos homens contra as mulheres pela morte impetrada ao jacaré, da mesma forma que, no ritual do xerimbabo, toma-se macaloba para descontar a morte do animal de criação, associado ao dono da festa.

Beber até cair e matar jacaré são demonstrações de coragem das mulheres. A coragem é um afeto associado à guerra e ao xamanismo (especialmente à iniciação), práticas eminentemente masculinas. No Wayo 'at Kanãa, as mulheres apropriam-se das capacidades agentivas - matar jacaré, beber exorbitantemente e exibir coragem - associadas ao espaço convencional ${ }^{15}$ masculino.

Apropriar-se talvez não seja o melhor termo para designar esse movimento, pois a agência masculina não é propriedade dos homens, ainda mais em regimes nos quais, como mostrou Strathern (1988), posse e propriedade não são a melhor forma de caracterizar as relações entre pessoas e coisas. Possivelmente, a agência masculina tende a ser melhor empregada por aqueles que tiveram seus corpos fabricados segundo o gênero masculino, como bem coloca McCallum (1999), quando discute a encorporação do conhecimento generificado entre os Kaxinawa. Porém, para que pessoas e coletivos possam se constituir, agência masculina e feminina precisam se combinar de diversas formas. Parece fazer parte desta complementaridade a possibilidade de que as pessoas experimentem os pontos de vista e a agência associada ao gênero oposto. O ritual é um espaço-tempo altamente privilegiado para este tipo de experimentação.

Se, por um lado, no Wayo 'at Kanã, as mulheres tomam para si capacidades masculinas, por outro lado, a face predatória que media a relação mãe-

15 Inspirada em Kelly (2009), por espaço convencional karo-arara, tenho em mente aquilo que, no processo dialético da simbolização delineado por Wagner (1981), aparece como da ordem do dado. Os regimes sociocosmológicos indígenas tendem a privilegiar um modo de simbolização ou ação que Wagner define como diferenciante, no qual as atividades consideradas como propriamente humanas e os modos tradicionais de agir e se comportar são tomados como inatos. Neste sentido, há uma forma karo-arara de ser homem, de ser mulher, de ser um casal, uma filha etc. Essas formas encontram-se no campo do dado na medida em que são percebidas como já constituídas, e não como produtos da ação humana. O que cabe a esta ação é atualizar essas formas e, ao mesmo tempo, diferenciar-se quanto ao grau e à excelência com que isso é feito. 
filho/marido aparece como axiomática e dada: não se trata de uma agência masculina empregada pelas mulheres. A predação não é uma afecção masculina, compondo também parte do corpo e da pessoa femininos. Ao fazer a raiva feminina simultaneamente aparecer e ser descartada, a festa contribui para o processo de desafinização das mulheres, realizado cotidianamente por meio do trabalho de produção de um tap. Assim, elas podem seguir sendo esposas de seus maridos e mães de seus filhos.

Nas terras baixas sul-americanas, o corpo é permanentemente fabricado de modo a adquirir uma forma apropriadamente humana, ou seja, semelhante à dos parentes e diferente à dos não humanos, especialmente os animais. Não há consubstancialização sem alteridade: a diferença é o fundo contra o qual a semelhança é fabricada. Nas palavras de Viveiros de Castro (2002b:448):

a criança precisa ser desafinizada: ela é um estranho, um hóspede a ser transformado em um consubstancial. A construção do parentesco é a desconstrução da afinidade potencial; mas a reconstrução do parentesco ao fim de cada ciclo deve apelar para esse fundo de alteridade dada que envolve a socialidade humana.

A "especiação" começa muitas vezes no processo de concepção, mas é, principalmente, com o parto e as regras de couvade que o trabalho de produção de um corpo humano se intensifica.
As restrições envolvem tabus alimentares e ações nas quais se empreende força ou violência, como caçar e trabalhar em qualquer etapa da roça. Entre os Karo-Arara, uma das formas de se referir a essas práticas diz respeito à condição da mulher: imoba $i^{\prime} \hat{u} t$ maxon nã, algo que poderíamos traduzir como "permanecer deitada para o filho ficar duro, forte". Trata-se de enrijecer os ossos do bebê por meio do controle do fluxo de substâncias entre os pais e a criança. O objetivo é, por um lado, impedir uma identificação do corpo da criança, ainda indiferenciado, com os corpos de outras espécies. Neste caso, as restrições dizem respeito às interações com os animais ou partes deles. Por outro lado, a evitação do empenho de força, também prescrita para esse período, visa a impedir que as ações impetradas sobre as coisas se repliquem no bebê.

Nos primeiros meses, a dieta alimentar dos pais fica restrita aos galináceos e aos peixes escamosos nos primeiros meses após o nascimento do filho. Jacaré, queixada e veado são carnes especialmente perigosas para o bebê. A fabricação do corpo de acordo com a espécie nunca cessa. Passado o período de maior incerteza quanto ao status humano da criança, inicia-se um conjunto de práticas que, em sua maioria, tomam os animais como vetor de semelhança, e não mais de diferença. O aprendizado da fala é facilitado pela ingestão de 
uma lagarta grande (nék), encontrada no tronco de algumas árvores, quando o bebê já anda e balbucia algumas palavras. Para terem dentes afiados e fortes - fundamental em uma dieta carnívora -, meninos e meninas tomam o sumo de uma folha apreciada pela onça e comem miolo de cotia.

Algumas restrições alimentares impostas aos pré-púberes têm como objetivo evitar diferentes comportamentos ou efeitos nos futuros homens e mulheres. Assim, se ingerido por uma menina, o marix $a^{16}$ quente pode causar evacuação durante o parto. Já os meninos evitam tomá-lo porque, caso o fizessem, sentiriam medo do queixada, tornando-se imprestáveis para a caça. A paçoca de milho, por sua textura seca, costuma ser evitada por meninas que ainda não menstruaram, para que não fiquem sem leite quando vierem a parir. Ela também é interdita para os meninos que ainda não passaram pela puberdade porque impediria a produção do sêmen. As substâncias têm, portanto, efeitos distintos nos corpos daqueles que estão no processo de devir homem e devir mulher.

Os corpos karo-araras são, assim, inicialmente fabricados como humanos contra não humanos e sem marcação de gênero. Com o passar dos anos, algumas práticas de fabricação corporal passam a produzir também uma diferenciação de gênero.
Ao longo da vida, a pessoa é incessantemente produzida como humana e como homem ou mulher, adquirindo agências e capacidades relacionadas a seu tipo de atuação no mundo.

Qual a implicação dessa dupla fabricação - do gênero e da humanidade - dos corpos? Há algum sentido em que homens e mulheres possam ser vistos como "espécies" distintas, isto é, como tipos distintos de gente? A etnografia de Belaunde sobre os Airo-Pai aponta nesta direção. Segundo a autora, do ponto de vista dos seres celestiais airo-pai, homens e mulheres são espécies distintas de pássaros. Os primeiros são japus, "pássaros carnívoros, cantores e tecedores de ninhos que ficam pendurados nos galhos das árvores. As mulheres são papagaiosverdes (Ama- zona sp.), comedoras de sementes e formam seus ninhos em buracos abertos nos troncos das árvores" (Belaunde 2006:209).

O procedimento totêmico dos deuses airo-pai sugere a existência de perspectivas a partir das quais os pontos de vista de homens e mulheres possam aparecer como completamente diferentes. Acredito que podemos extrair conclusões análogas a partir da análise do Wayo 'at Kanã, pois a festa varia entre momentos de divergência e equivalência entre os pontos de vista de homens e mulheres a respeito do jacaré. A depender das ações rituais e

16 Marixa é uma variedade de macaxeira, que dá nome à bebida considerada genuinamente karo-arara e raramente produzida na atualidade. É feita a partir do cozimento da macaxeira ralada e reportada como tendo baixo teor alcóolico, quando comparada à $n a^{\prime}$ mếk kap, receita gavião onipresente nas casas karo-araras no presente, porém, em sua versão doce. 
do gênero dos participantes, o animal é espíritoamante/espírito-inimigo/presa.

Com exceção do casal não indígena que dançou junto segurando os jacarés, em todas os outros momentos de dança com os animais capturados, eles foram carregados por duplas ou trios de mesmo sexo. Assim, entendo que, durante as danças que antecedem o sacrifício animal, $o$ jacaré existe para os homens ou para as mulheres, nunca para os dois simultaneamente. Ele é um filhoamante para as mulheres, que dançam com ele no colo, e inimigo espiritual para os homens. É por isso que os caçadores batem com paus no chão e assoviam, simulando atos guerreiros praticamente em todas as vezes que se aproximam do animal. A fala do pajé dirigida às matadoras e aos demais participantes da festa antes de elas executarem os animais principia a produção de uma perspectiva desvinculada do gênero. O bichano aparece, então, como filho da mãe para mulheres e homens quando o pajé anuncia que aquela mulher irá matá-lo porque ela judia do filho, para que ela comprove sua coragem diante de todos. O repasto que encerra a festa, quando todos consomem o caldo de jacaré, preparado por uma cozinheira designada pelo dono ou pela dona da festa, sinaliza o devido lugar do jacaré de um ponto de vista humano: o de presa.

O ritual alterna, assim, diferentes pontos de vista para, ao final, produzir uma espécie de consenso entre homens e mulheres. Eclipsando as perspectivas generificadas, um ponto de vista humano indiferente ao gênero é elicitado: com a barriga cheia, homens e mulheres concordam que o jacaré é comida.

A diferença de perspectiva não se restringe à socialidade ritual. Um investimento etnográfico de maior fôlego ainda é necessário quanto a esse ponto, mas o gênero da perspectiva certamente também influencia a socialidade cotidiana. Por muito tempo, tive dificuldades de compreender a natureza das roças no espaço-tempo da maloca (Otero dos Santos 2016). Homens e mulheres mais velhos contam que havia uma única roça por unidade habitacional. As mulheres, contudo, afirmam que cada mulher tinha uma parte onde podiam plantar e colher. De alguma maneira, isso refere-se às formas de produção: homens derrubavam e queimavam uma área contínua junto com outros homens; os esforços produtivos das mulheres materializariam na terra contínua alguma divisão familiar, pois cada mulher tinha uma parte. Os homens "trocam" trabalho; as mulheres trocam os produtos do resultado de seus esforços produtivos.

Apesar de falarem de domínios familiares da roça, essas mesmas mulheres recusam a imagem de uma terra dividida em favor de uma única e grande roça, principalmente quando falam que: 
i) antigamente uma mulher convidava as outras para colheitas em sua roça, mesmo em ocasiões não rituais, ou ii) que todo mundo comia junto. $\mathrm{A}$ divergência de perspectiva de homens e mulheres quanto às roças é eclipsada em favor de uma imagem não generificada da roça como produto do parentesco. Algo parecido com o que se passa no Wayo 'at Kanã, em que uma perspectiva humana não generificada - um acordo de perspectivas entre homens e mulheres sobre o jacaré - é ativa e deliberadamente produzida. A vida karo-arara parece, assim, alternar-se entre a divergência e a convergência de perspectivas de homens e mulheres. Dito de outro modo, homens e mulheres aparecem ora como humanos sem gênero, ora como espécies distintas; uma tal formulação do gênero da perspectiva, aliás, já havia sido antecipada por Belaunde (2005:17-18) em sua discussão sobre reprodução paralela e reprodução cruzada:

\begin{abstract}
Desde esse ponto de vista, os homens e as mulheres são dois tipos de seres humanos e levam vidas paralelas, cada qual reproduzindo-se a si mesmo, produzindo comida e artefatos e manejando conhecimentos próprios. Desde outro ponto de vista, os homens e as mulheres são um mesmo ser humano e reproduzem-se cruzando, cada qual contribuindo com seus alimentos, seus artefatos e seus conhecimentos para a geração de uma vida comum.
\end{abstract}

Essa observação de Belaunde contém uma intuição, a meu ver, bastante profunda e pouco explorada no campo etnológico. Ela capta uma questão possivelmente muito mais geral: como compor um mundo comum a partir dos pontos de vista - distintos - de homens e mulheres? Quando as mulheres mais velhas me dizem que, no espaço-tempo da maloca, todo mundo comia junto, esse todo mundo é difracionado, pois homens e mulheres comiam separadamente. Pensando na importância da comensalidade na fabricação dos corpos, isso aponta para uma diferenciação ontológica entre homens e mulheres, a mesma que faz vários desses povos se perguntarem, como coloca Belaunde (2005), como uma mulher pode ter um filho homem ou um homem ter uma filha mulher.

O problema que se coloca aqui é o do gênero como perspectiva, algo anunciado por Belaunde e desenvolvido por Lima (2005), e sobre o qual a etnografia da festa karo-arara também pode lançar algum entendimento. Uma releitura das etnografias das terras baixas sul-americanas à luz desse problema certamente nos oferecerá uma compreensão do gênero que não o tome, como o fez Descola (2001), como invariavelmente subsumido nas relações de consanguinidade e afinidade ou nas relações entre humanos e não humanos (animais). O caso aqui tratado justamente supõe uma relação com o jacaré e com a roça determinada pelo gênero da perspectiva. 


\section{AGRADECIMENTOS}

Baseado no capítulo 5 da minha tese de doutorado (Otero dos Santos 2015), este artigo tem uma longa história. Uma versão inicial foi apresentada na mesa redonda "Gênero na cosmopolítica ameríndia: casos etnográficos em debate”, coordenada por Beatriz Matos, no 40 Encontro Anual da ANPOCS, em 2016. Partes dele também foram discutidas nos seminários "Casa, corpo e políticas da terra", organizados por Ana Carneiro, Graziele Dainese e Márcia Nóbrega, em Brasília, em 2018, e em Porto Seguro, em 2019.
Agradeço às discussões e aos comentários ao texto nas três ocasiões. Não sou capaz de mensurar o quanto a versão final ora apresentada é fruto do diálogo com Beatriz Matos, que tecemos juntas desde 2016. Agradeço a Bia pela generosidade, pelo incentivo e pelo compartilhamento de suas ideias. Também agradeço a leitura atenta e os comentários de Luisa Belaunde e Marcela Coelho de Souza à versão deste artigo submetida para publicação. Qualquer equívoco é de minha inteira responsabilidade.

\section{REFERÊNCIAS}

Belaunde, L. 1994. Parrots and Oropendolas: the Aesthetics of gender relations among the Airo-Pai of the Peruvian Amazon. Journal de la Société des Américanistes 80:95-111.

Belaunde, L. 2001. Viviendo bien: género y fertilidad entre los airopai de la Amazonía peruana. Lima: Centro Amazónico de Antropología y Aplicación Práctica y Banco Central de Reserva del Perú.

Belaunde, L. 2005. El recuerdo de luna: género, sangre y memoria entre los pueblos amazónicos. Lima: Fondo Editorial de la Facultad de Ciencias Sociales.

Belaunde, L. 2006. A força dos pensamentos, o fedor do sangue. Hematologia e gênero na Amazônia. Revista de Antropologia 49(1):205-243. DOI: http://dx.doi.org/10.1590/S0034-77012006000100007.

Belaunde, L. 2015. O estudo da sexualidade em etnologia. Cadernos de Campo 24:399-411. DOI: https:// doi.org/10.11606/issn.2316-9133.v24i24p399-411.

Dal Poz, J. 1991. No país dos Cinta-Larga: uma etnografia do ritual. Dissertação de Mestrado, Universidade 
de São Paulo, Departamento de Antropologia, São Paulo.

Descola, P. 2001. The genres of gender: local models and global paradigms in the comparison of Amazonia and Melanesia, in Gender in Amazonia and Melanesia: an exploration of comparative method. Organizado por I. T. Gregor e D. Tuzin, pp. 91-114. Berkeley: University of California Press.

Gow, P. 1989. The perverse child: desire in a native Amazonian subsistence economy. Man 24(4):567582. DOI: http://dx.doi.org/10.2307/2804288.

Gregor, T. 1985. Anxious pleasures: the sexual lives of an Amazonian people. Chicago: Chicago University Press.

Kelly, J. A. 2009. Yãnomami, doctors and the State: the cosmopolitics of Indian-White relations in Venezuela. Tese de Doutorado, Universidade de Cambridge, Departamento de Antropologia Social, Cambridge.

Lasmar, C. 1996. Antropologia feminista e etnologia amazônica: a questão do gênero nas décadas de 70 e 80. Dissertação de Mestrado, Museu Nacional/Universidade Federal do Rio de Janeiro, Departamento de Antropologia Social, Rio de Janeiro.

Lasmar, C. 1999. Mulheres indígenas: representações. Revista Estudos Feministas 7(1-2):1-14.

Lasmar, C. 2005. De volta ao lago de leite: gênero e transformação no alto Rio Negro. São Paulo: Editora UNESP/ISA; Rio de Janeiro: NUTI.

Lasmar, C. 2008. Irmã de índio, mulher de branco: perspectivas femininas no alto rio Negro. Mana 14(2):429-454. DOI: http://dx.doi.org/10.1590/S0104-93132008000200006. 
Lévi-Strauss, C. 2004a. O cru e o cozido. São Paulo: Cosac \& Naify.

Lévi-Strauss, C. 2004b. Do mel às cinzas. São Paulo: Cosac \& Naify.

Lima, T. S. 1996. O dois e seu múltiplo: reflexões sobre o perspectivismo em uma cosmologia tupi. Mana 2(2):21-47. DOI: http://dx.doi.org/10.1590/S0104-93131996000200002.

Lima, T. S. 2002. O que é um corpo? Religião e Sociedade 22:9-19.

Lima, T. S. 2005. Um peixe olhou pra mim: os Yudjá e a perspectiva. São Paulo: ISA/Unesp.

MacCormack, C., e M. Strathern. 1980. Nature, culture and gender. Cambridge: Cambridge University Press.

Matos, B. 2017. Caminhos e malocas: conjuntos na Amazônia Ocidental. R@u - Revista de Antropologia da Ufscar 9(1):37-60.

McCallum, C. 1999. Aquisição de gênero e habilidades produtivas: o caso Kaxinawá. Revista Estudos Feministas 7(1-2):157-175.

McCallum, C. 2001. How real people are made. Gender and sociality in Amazonia. Oxford: Berg.

Métraux, A. 1979. A religião dos Tupinambás. 2. ed. São Paulo: Companhia Editora Nacional.

Mindlin, B., T. Digüt, e S. Catarino. 2001. Couro dos espíritos: namoro, pajés e cura entre os índios Gavião-Ikolen de Rondônia. São Paulo: Terceiro Nome e Senac.

Murphy, Y, e Murphy, R. 1974. Women of the forest. Nova York/Londres: Columbia University Press. 
Ortner, S. B. 1974. Is female to male as nature is to culture?, in Woman, culture, and society. Editado por M. Z. Rosaldo, e L. Lamphere, pp. 68-87. Stanford, CA: Stanford University Press.

Otero dos Santos, J. 2014. Ritual, "cultura” e transformação: a Festa do Jacaré entre os Arara de Rondônia, in Políticas culturais e povos indígenas. Organizado por M. C. Cunha, e P. N. Cesarino, pp. 135-63. São Paulo: Cultura Acadêmica.

Otero dos Santos, J. 2015. Sobre mulheres brabas, parentes inconstantes e a vida entre outros: a Festa do Jacaré entre os Arara de Rondônia. Tese de doutorado, Universidade de Brasília, Departamento de Antropologia, Brasília.

Otero dos Santos, J. 2016. Bebida, roça, caça e as variações do social entre os Arara de Rondônia. Espaço Ameríndio 10(2):118-161. DOI: https://doi.org/10.22456/1982-6524.64261.

Overing, J. 1986. Men control women? The catch-22 in gender analysis. International Journal of Moral and Social Studies 1(2):135-156.

Seeger, A., R. Da Matta, e E. Viveiros de Castro. 1979. A construção da pessoa nas sociedades indígenas brasileiras. Boletim do Museu Nacional, Série Antropologia (32):2-19.

Strathern, M. 1988. The gender of the gift problems with women and problems with society in Melanesia. Berkeley: University of California Press.

Strathern, M. 2014. Sem cultura, sem natureza: o caso Hagen, in O efeito etnográfico e outros ensaios, pp. 23-74. São Paulo: Cosac Naify.

Viveiros de Castro, E. 1979. A fabricação do corpo na sociedade xinguana. Boletim do Museu Nacional (32):40-49. 
Viveiros de Castro, E. 1996. Os pronomes cosmológicos e o perspectivismo ameríndio. Mana 2(2):115144. DOI: http://dx.doi.org/10.1590/S0104-93131996000200005.

Viveiros de Castro, E. 2002a. O problema da afinidade na Amazônia, in A inconstância da alma selvagem, pp. 87-180. São Paulo: Cosac \& Naif Edições.

Viveiros de Castro, E. 2002b. Atualização e contra-efetuação do virtual: o processo do parentesco, in $A$ inconstância da alma selvagem, pp. 401-455. São Paulo: Cosac \& Naif Edições.

Wagner, R. 1981. The Invention of Culture. Chicago: The University of Chicago Press. 